\title{
A Atualidade do Pensamento Cepalino Do Estruturalismo ao Neoestruturalismo
}

http://dx.doi.org/10.21527/2237-6453.2021.54.10-27

Recebido em: $17 / 2 / 2020$

Aceito em: 26/10/2020

Beliza Borba de Almeida ${ }^{1}$, Ivan Colangelo Salomão ${ }^{2}$

\section{RESUMO}

O presente trabalho procura analisar as modificações ocorridas no pensamento da Comissão Econômica para a América Latina e Caribe que justificaram a denominação de uma teoria neoestruturalista após a década de 90 do século 20. 0 ideário estruturalista cepalino foi sendo adaptado ao longo do tempo, culminando com as proposições neoestruturalistas, consideradas o novo paradigma da instituição até os dias de hoje. Busca-se, assim, entender quais as mudanças apresentadas no projeto de desenvolvimento cepalino nas últimas duas décadas, bem como analisar se a heterodoxia presente nos estudos originais prevalece ainda hoje nos trabalhos da comissão.

Palavras-chave: Cepal. Estruturalismo. Neoestruturalismo.

\section{THE CURRENT STATUS OF ECLAC THINKING: FROM STRUCTURALISM TO NEO-STRUCTURALISM}

\section{ABSTRACT}

The present paper seeks to analyze the changes that occurred in the thinking of the Economic Commission for Latin America and the Caribbean that justified the name of a neo-structuralist theory after the 1990s. The Eclac structuralist ideology was being adapted over time culminating in the neostructuralist propositions, considered as the new paradigm of the institution until today. Thus, we seek to understand what changes have been made in the ECLAC's development project in the last two decades, as well as to analyze whether the heterodoxy present in the original studies still prevails today in the work of the commission.

Keywords: Eclac. Structuralism. Neostructuralism.

\footnotetext{
${ }^{1}$ Universidade Federal do Paraná (UFPR). Curitiba/PR, Brasil.

${ }^{2}$ Autor correspondente. Universidade Federal do Paraná (UFPR). Rua XV de Novembro, 1299 - Centro. CEP 80060-000. Curitiba/PR, Brasil. http://lattes.cnpq.br/9840246719284048. https://orcid.org/0000-0001-5857-7505. ivansalomao@gmail.com
} 
Até o início dos anos 1950, o desenvolvimento econômico, como objeto de estudo, esteve condicionado à análise da experiência de acumulação de capital e progresso técnico das ditas sociedades desenvolvidas, como a europeia e a norte-americana. Tais estudos focavam na possibilidade de catching up das economias periféricas, entendendo o subdesenvolvimento como uma etapa a ser superada, desconsiderando diferenças estruturais entre os países.

Os modelos até então discutidos não abordavam a dimensão histórica do desenvolvimento econômico. Nesse sentido, supor a revolução industrial e a modificação do paradigma de produção subjacente à experiência inglesa como o único caminho de desenvolvimento a ser seguido - por qualquer país, em qualquer contexto - mostrava-se uma perspectiva limitada e irreal para a América Latina.

Assim, com o intuito de melhor entender a diferença entre os processos de desenvolvimento observados nas nações hoje dominantes e nos países subdesenvolvidos, a criação da Comissão Econômica para a América Latina e o Caribe (Cepal), no final dos anos 1940, contribuiu para o estabelecimento de uma teorização própria à realidade latino-americana. Para Furtado (1961), derivar um modelo abstrato do mecanismo daquelas economias, em seu estágio atual, e atribuir-Ihe validez universal, valeria por uma reencarnação do homo economicus, em cuja psicologia rudimentar os clássicos pretenderam assentar as leis econômicas fundamentais.

Compreender o subdesenvolvimento como processo histórico, autônomo e decorrente da própria forma de expansão das economias já desenvolvidas era o desafio dos economistas latino-americanos que integraram a Cepal logo após a sua criação, como Raúl Prebisch e Celso Furtado. O período foi marcado pela ampla discussão em torno de novas teorias de desenvolvimento econômico, visando a entender a enorme disparidade na distribuição de renda entre os países e o problema da concentração de renda. Consideradas como imposições de "fora para dentro", as teorias dominantes eram definidas como esquemas explicativos dos processos sociais, em que a mera assimilação de novas técnicas e o consequente aumento de produtividade conduziria à melhoria do bem-estar de uma população com crescente homogeneização social (FURTADO, 1985).

Na perspectiva cepalina, portanto, o problema do subdesenvolvimento estaria relacionado às próprias estruturas dos países, as quais acarretariam uma deficiência na assimilação do progresso técnico e impossibilitariam a homogeneidade social. Analisar o processo que levou ao subdesenvolvimento da América Latina seria contextualizar historicamente as estruturas econômicas e sociais desses países. Nesse sentido, a Cepal mostrou-se, ao longo dos 70 anos de sua existência, um centro de pensamento cujas ideias e análises evoluíram no decorrer do tempo, buscando cotejar a teoria econômica à realidade da região.

De acordo com Bielschowsky (2000), as análises iniciais apresentadas nos anos 1950 defendiam, primordialmente, a industrialização dos países periféricos como forma de alcançar o desenvolvimento e solucionar os problemas de estrangulamento externo variável -, esta central para o modelo de substituição de importações. A partir de 1960, a comissão passou a incluir a proposição de reformas para desobstruir a industrialização, posto que alguns processos já iniciados apresentavam problemas de continuidade. 
Os trabalhos cepalinos da década de 70 do século 20 tiveram como base uma reorientação dos modelos de desenvolvimento propostos, uma vez que se passou a incentivar uma industrialização pró-exportadora. Ou seja, partindo das experiências fechadas de substituição de importações, fez-se necessário buscar uma industrialização também "para fora". Ademais, o problema de endividamento externo, em razão da modificação na forma de financiamento da industrialização, passou a atrair a atenção dos técnicos da comissão a partir dos anos 1980.

Já na última década do século 20, Bielschowsky (2000) define a busca de uma transformação produtiva com equidade como tema principal dos escritos cepalinos da década de 90 . O foco, então, não estava mais na industrialização visando o mercado interno, uma vez que o processo de abertura comercial em voga nos países do subcontinente condicionou a condução de toda a política econômica local. Outra diferenciação entre os estudos apresentados pela Cepal a partir dessa época diz respeito ao chamado neoestruturalismo, o qual pode ser considerado uma renovação nos modos de conceitualizar o progresso técnico. As análises passam a tratar do desenvolvimento não apenas como um fenômeno de longo prazo, mas como um processo integralizado e articulado aos problemas de curto prazo inerentes aos ajustes econômicos. Nesse sentido, a abordagem é adaptada ao contexto histórico da globalização.

Diante dos elementos supracitados, este trabalho tem por objetivo apresentar as teorias cepalinas neoestruturalistas desenvolvidas a partir dos anos $1990^{3}$. Com as modificações das relações comerciais ocorridas à época, aliada à onda neoliberal da última década do século 20, fez-se necessário reformular e atualizar o arcabouço teórico com o qual a Cepal analisava a realidade latino-americana. Busca-se, assim, entender quais as mudanças apresentadas no projeto de desenvolvimento cepalino nas últimas duas décadas, bem como analisar se a heterodoxia, presente nos estudos originais, prevalece ainda hoje nos trabalhos da comissão.

Para tanto, utilizar-se-á de determinados documentos publicados pelo órgão no decorrer da década de 50 , os quais foram sumarizados pelo trabalho seminal de Rodríguez (2009). No que diz respeito à atualização do pensamento cepalino, o artigo baseou-se em trabalhos originais da comissão disponibilizados em seu repositório e, sobretudo, no compêndio igualmente importante organizado por Bielschowsky (2000).

\section{O NEOESTRUTURALISMO CEPALINO}

A partir da crise econômica observada em toda a América Latina durante a década de 80 , os estudiosos da Cepal notaram a necessidade de se reformular o projeto de desenvolvimento proposto pela comissão. A estratégia de industrialização via substituição de importações não proporcionara o crescimento esperado, reforçando, ainda, o problema do endividamento e a inflação generalizada. O desemprego e o subemprego

\footnotetext{
3 O trabalho de Missio e Jayme Junior (2012) traz elementos importantes que contribuem para alargar o entendimento do objeto em análise neste artigo. Conquanto os autores apresentem argumentos que vão ao encontro dos aqui defendidos, o foco daquele recai sobre os conceitos de competitividade sistêmica e ciclo virtuoso. Em comum, ambos os trabalhos concluem que a globalização do final do século 20 impõe condicionantes relevantes, mas não determinantes, para as trajetórias de desenvolvimento das economias latino-americanas.
} 
haviam aumentado significativamente, demonstrando não ter havido a esperada assimilação da mão de obra pelo setor industrial. A época também foi caracterizada pela ascensão de ideias neoliberais no contexto global e de críticas ao projeto industrializante.

O pensamento cepalino passou a posicionar-se ante a tais críticas e, a partir das teses estruturalistas, propor os novos caminhos da industrialização e mudanças na forma de ação do Estado. Tal ponto de inflexão é considerado a vertente neoestruturalista da Cepal, segundo a qual o modelo de crescimento "para dentro" deveria ser revisto em resposta aos fortes desequilíbrios inflacionários. Se a condição periférica dos países da América Latina perpetuava-se, era necessário renovar a análise e propor novas estratégias de desenvolvimento para a região.

O novo foco da análise estava na aceleração das exportações visando a conter os desequilíbrios externos, bem como em fomentar a integração econômica e a incorporação de progresso técnico. A dicotomia estruturalista centro-periferia deveria ser ampliada considerando a mudança na forma de inserção internacional na era da globalização. Ademais, o foco social é aprofundado ao propor-se a inclusão dos países que permaneceram excluídos dos benefícios do progresso tecnológico. O surgimento de diferentes formas ocupacionais, como a terceirização da mão de obra, também requeria uma nova conceituação.

A questão cultural, especialmente tratada por Celso Furtado (1984), também auferiu maior importância na análise da estrutura social, tornando-se um dos principais vetores nos escritos pós-1980. Nesse aspecto, o perfil dos agentes econômicos passou a considerar o papel fundamental da liderança do empresariado nacional no processo de aprendizado e de incorporação do progresso técnico que não fosse mera imitação dos países centrais.

O crescimento industrial observado na região, principalmente nos anos 1970, não foi capaz de promover a inclusão social esperada. A concentração de renda e de poder culminou, na década seguinte, no agravamento das desigualdades e na proliferação do subemprego, sendo a economia incapaz de absorver a rápida expansão do setor urbano. A partir daquele momento, entendeu-se que o estilo de desenvolvimento promovido até então necessitava ser revisto.

A nova visão do progresso técnico, agora endógeno ao sistema econômico e às atividades produtivas, que estava sendo delineada na literatura do desenvolvimento, também influenciou o pensamento cepalino a adaptar suas teses. A abordagem do progresso endógeno privilegia a organização das empresas na propagação da tecnologia bem como as peculiaridades da economia e sociedade do país. Nesse sentido, para o neoestruturalismo surge a importância do papel organizacional, assim como do elemento empresarial na propagação da tecnologia e sua relação com os agentes públicos.

O processo de globalização e transnacionalização financeira do período também marca um novo padrão da divisão de trabalho internacional, sendo necessário analisar as modificações causadas na dicotomia centro-periferia nesse novo cenário. A defesa da industrialização também ganharia nova roupagem, "uma industrialização imbricada entre centros e periferia, que uma parte da indústria se desenvolvesse no primeiro polo do sistema, e outro lado no segundo" (RODRíGUEZ, 2009, p. 559). 
Assim, os textos publicados pela comissão após 1990 são considerados o ponto de inflexão do estruturalismo ao neoestruturalismo. Serão analisadas, a seguir, as principais contribuições do novo paradigma cepalino na análise do desenvolvimento latino-americano e quais as modificações propostas ao processo de industrialização, e também quão heterodoxas podem ser consideradas tais propostas.

\section{O DESENVOLVIMENTO APÓS 1980}

O desenvolvimento industrial ocorrido na América Latina até a década de 80 , deu-se mediante grande endividamento externo. O documento cepalino "Políticas de ajuste e renegociação da dívida externa da América Latina", publicado em 1984, identificou a necessidade de uma combinação adequada de políticas econômicas condizentes com a realidade de cada economia, na tentativa de resolver o déficit externo. Em alguns países as causas do desequilíbrio externo advinham de uma expansão excessiva de gastos; já em outros, da manutenção de baixas taxa de câmbio (CEPAL, 2000a).

O endividamento generalizado dos países periféricos era visto como um problema de ordem pública, devendo haver uma "repartição dos custos" e uma solução coletiva entre os países tomadores de empréstimos, bancos transnacionais e governos da Organização para a Cooperação e Desenvolvimento Econômico (Ocde). De acordo com o documento mencionado, "os países da América Latina se endividaram conforme suas próprias necessidades e decisões, mas atendendo também ao estímulo de alguns argumentos que estavam em voga em importantes círculos técnicos internacionais, no sentido de que os créditos bancários eram 'baratos' em termos reais e de que o endividamento externo era um bom negócio" (CEPAL, 2000a, p. 791).

A ideia principal na recuperação das economias periféricas era a de um interesse comum, tanto dos credores quanto por parte dos devedores, em reduzir o desemprego e as tensões sociais sem comprometer os lucros das instituições emprestadoras. Para tanto, era considerada necessária a redução de certo protecionismo industrial vigente, bem como novos acordos bilaterais no sentido de uma reprogramação da dívida com as instituições financeiras internacionais.

O crescimento dos países no período anterior a 1980 ocorreu, como já observado, sob forte endividamento externo. Tal estratégia, no entanto, resultou na expansão do consumo e não exatamente no aumento da capacidade produtiva. Além disso, a época foi marcada por uma modificação nas relações do setor produtivo não financeiro com o setor financeiro, havendo uma proliferação de bancos transnacionais e, consequentemente, o fortalecimento do capitalismo financeiro.

Em documento de 1985 - "Transformação e crise na América Latina e Caribe 1950-1984" - a Cepal tratou dos problemas gerados pela financeirização do capital e separação entre funções produtivas empresariais e financeiras, realizando uma crítica de viés keynesiano à subordinação do setor produtivo ao financeiro e ao caráter "especulativo e monopolista do capitalismo" (CEPAL, 2000b, p. 837). O tema é tratado como uma nova modalidade de inserção internacional dos países periféricos, perdendo o setor público o controle sob os aspectos financeiros dominados pelos bancos transnacionais. A análise conjuntural apresentada pela Cepal demonstra a busca por políticas neoliberais 
e o consequente agravamento da crise em diversos países da América Latina. Nesse sentido, o processo de renegociação, iniciado em 1981, foi acompanhado de políticas de ajuste interno e descrito pela Cepal em 1985 da seguinte forma:

Nesses processos, houve uma participação ativa dos governos da região, dos bancos transnacionais e do Fundo Monetário Internacional. Os bancos transnacionais não reconheceram sua co-responsabilidade na situação e, como é natural em quem adota essa postura, envidaram maiores esforços internos no sentido de garantir uma capacidade maior de pagamentos externos. Por isso, condicionaram a renegociação da dívida à assinatura de convênios com o Fundo, convênios estes que incorporaram as conhecidas regras de condicionalidade das políticas internas (CEPAL, 2000b, p. 846).

Os questionamentos gerados à época estavam justamente na eficácia das medidas macroeconômicas ortodoxas exigidas pelos organismos internacionais na concessão de empréstimos, bem como na limitação do setor público na intervenção econômica. 0 prolongamento da recessão nos países periféricos após a década de 80 exacerbou ainda mais a condição heterogênea, o problema inflacionário e o processo de desindustrialização da região. O ajuste adotado havia sido "pouco eficiente, destrutivo e injusto, o que obriga a que seja submetido a uma profunda revisão" (CEPAL, 2000b, p. 849). A posição cepalina em 1985 era a de buscar uma distribuição equitativa dos custos externos e internos da crise, visando a uma reativação da economia da região.

O novo paradigma do pensamento neoestruturalista colocou-se, então, como uma nova etapa do pensamento cepalino, na qual elementos do estruturalismo original coadunaram-se à nova realidade de ajustes neoliberais e às ideias dominantes do Consenso de Washington ${ }^{4}$. A nova análise da realidade latino-americana deveria buscar tanto a superação das teses iniciais que não se mostraram eficazes quanto as neoliberais, apresentadas como soluções impostas pelos países centrais. Nesse sentido, o estruturalismo deveria ser revisto para se manter condizente como método histórico em épocas de abertura comercial e globalização, buscando soluções de curto prazo para os novos problemas enfrentados pela região.

As mudanças estruturais como condição para o desenvolvimento e a consideração do caráter histórico do subdesenvolvimento continuaram, pois, em pauta. A nova aproximação do problema, no entanto, considerava uma diferente forma de ação estatal, atuando em conjunto com o mercado e a sociedade no sentido de uma "fusão schumpeteriana-estruturalista", buscando reorientar a modalidade exportadora para os bens de maior conteúdo tecnológico e melhorar as cadeias produtivas (BIELSCHOWSKY, 2009). O padrão de inserção externo dos países periféricos continuava conduzindo a uma especialização produtiva. Dessa forma, tanto a particularização quanto o caráter heterogêneo da difusão do progresso técnico continuavam temas importantes a serem analisados. 0 crescimento ocorrido na região até a década de 90 não foi capaz de incluir grande parte da população, exacerbando, também, o problema da desigualdade.

\footnotetext{
${ }^{4}$ Nome dado ao conjunto de medidas de austeridade formuladas em 1989 e que se tornaram política oficial do FMI para a América Latina. As medidas envolviam privatizações, flexibilização do trabalho, abertura comercial, disciplina fiscal, reforma tributária, dentre outras.
} 
As reformas de longo prazo, visando o desenvolvimento da base produtiva e a estabilidade macroeconômica, bem como a construção de uma sociedade mais justa e igualitária, passam a ser as prioridades no pensamento neoestruturalista. O documento, considerado chave da nova abordagem da década de 90 - "Transformación productiva con equidad" -, propunha uma revisão da abertura financeira além de aplicação de novas políticas industriais e tecnológicas ${ }^{5}$. A transformação da estrutura produtiva deveria, assim, ser acompanhada por medidas redistributivas complementares na tentativa de promover a equidade.

Para Fajnzylber (2000), o desenvolvimento ocorrido na região até então era fruto mais da imitação do que de um processo de reflexão sobre as carências e potencialidades internas de cada país. Nesse sentido, o conceito de cultura é retomado na tentativa de compreender as particularidades regionais que auxiliem na superação da desigualdade e na busca de um pensamento original para definir as transformações produtivas necessárias. Indo além, o autor considerava que o desenvolvimento só seria uma realidade se não houvesse exclusão social. Nos termos empregados por Fajnzylber (2000, p. 871), era "uma ilusão aspirar a essa participação (na economia internacional) excluindo parcialmente certos setores sociais e certas regiões, uma vez que as tensões sociais latentes traduzem-se inexoravelmente em incerteza e, em última instância, comprometem o investimento e o crescimento".

A modernização das instituições e das relações entre os agentes públicos e privados também se apresentava como imprescindível para a propagação e absorção do progresso técnico. A modificação na ação estatal foi considerada uma forma de "flexibilizar" as ideias estruturalistas em um contexto de ascensão neoliberal; mantinha-se a fidelidade, porém, ao método histórico, buscando manter a influência cepalina na região que havia sido abalada nos anos 1980. Assim, o Estado deveria atuar estrategicamente no sentido de dinamizar o mercado e corrigir as suas falhas, operando conjuntamente com a esfera privada, além de buscar o equilíbrio macroeconômico e a equidade social.

Outra novidade na abordagem neoestruturalista é a adoção de uma agenda de caráter global, transbordando a conceituação centro-periferia para a análise de uma inserção globalizada, até então desfavorável à América Latina, a partir de uma visão social de direitos dos cidadãos. Nessa abordagem, a superação do subdesenvolvimento depende também da ajuda das economias superavitárias, as quais deveriam investir seus excedentes nos países latino-americanos, buscando, também, uma integração Norte-Sul. Tal agenda de entendimento global passa a demonstrar maior consonância com os objetivos da Organização das Nações Unidas (ONU), à qual a Cepal é subordinada.

A preocupação com a sustentabilidade ambiental também se faz presente no neoestruturalismo, buscando alternativas de desenvolvimento para os países da América Latina de modo a garantir inclusão social juntamente com a conservação do meio ambiente. Nesse sentido, os problemas ambientais e a utilização dos recursos naturais também são analisados a partir de um viés estruturalista, e os objetivos conflitantes entre sustentabilidade e ganhos econômicos devem ser contrabalanceados pelo Estado.

\footnotetext{
${ }^{5}$ A redação do documento foi coordenada por Fernando Fajnzylber, economista chileno, à época diretor da Divisão de Indústria e Tecnologia da Cepal e um dos principais responsáveis pelas mudanças nas ideias da comissão.
} 
A reativação das economias da região dependeria, ainda, da cooperação entre os agentes públicos nacionais e internacionais, buscando acordos multilaterais dentro da própria América Latina e com países industrializados. Assim, a única possibilidade de manter uma expansão ordenada e sustentada da economia mundial dependeria de novas formas de desenvolvimento que resultassem em benefícios tanto para os países desenvolvidos quanto para os em desenvolvimento (CEPAL, 1996).

\section{INDUSTRIALIZAÇÃO EM CONTEXTO NEOLIBERAL}

O processo de industrialização, ocorrido até então, deveria ser revisto ante os novos desafios e às falhas não corrigidas, tais como o foco no mercado interno e a persistência de uma inserção no comércio internacional pela via de produtos primários. A indústria continuava sendo considerada o setor de maior potencial de difusão do progresso técnico. Ainda assim, deveria ser capaz de se articular com os demais setores da economia, permitindo uma maior acumulação, eficiência produtiva e difusão da tecnologia. Outro fator importante, além do foco no mercado interno ou externo, estava na organização industrial, conforme argumentam Sunkel e Zuleta (1990, p. 43):

(...) lo crítico no es tanto la demanda; lo verdaderamente crítico es un esfuerzo dinámico de oferta: acumulación, calidad, flexibilidad, combinación y utilización eficiente de los recursos productivos, incorporación deliberada del progreso técnico, esfuerzo innovador y creatividad, capacidad organizativa, articulación y disciplina social, frugalidad en el consumo privado y público y acento en el ahorro nacional, así como la adquisición de capacidad para insertarse dinámicamente en la economía mundial. En suma, con la participación activa del Estado y de los agentes privados, desplegar un esfuerzo propio y deliberado, "desde dentro", para lograr un desarrollo autosustentado.

Novas estratégias de industrialização deveriam, então, ser adotadas, visando primordialmente o fortalecimento de uma classe empresarial nacional que pudesse, posteriormente, conduzir tal processo. O elevado grau de transnacionalização das empresas e o avanço de políticas neoliberais no cenário global também haviam gerado uma nova realidade para a divisão internacional do trabalho. A nova industrialização proposta deveria abarcar essas modificações, propondo uma nova forma de desenvolvimento a longo prazo.

A simples imitação das técnicas produtivas dos países industrializados tinha se mostrado incapaz de gerar eficiência produtiva em razão da debilidade dos processos de aprendizagem e da baixa criatividade dos condutores do processo. O conceito de criatividade é entendido a partir da ideia de cultura desenvolvida por Furtado (1984): uma atitude para a concretização do aprendizado. Essa atitude estaria na base da atividade científica geral, das manifestações culturais e da política, e seria o fator-chave para o impulso da aprendizagem e mudanças na estrutura industrial e produtiva (RODRÍGUEZ, 2009, p. 515).

A atitude criativa seria o principal fator na adaptação e apreensão do progresso técnico originado nos países centrais. A nova industrialização deveria ser capaz de gerar um padrão interno industrial e tecnológico por meio da articulação entre criatividade 
e aprendizagem. A matriz industrial, assim gerada, deveria focar em áreas estratégicas para o crescimento da região, fazendo com que o setor de bens de capital se articulasse com o agrícola - de modo a superar métodos arcaicos - e com o energético.

A nova industrialização deveria, então, promover um crescimento a partir de uma atitude criativa, entendida como inovação tecnológica e novas formas de organização industrial (FURTADO, 1978). O conjunto do sistema produtivo deveria ser integrado, formando núcleos endógenos de progresso técnico e permitindo corrigir a assimetria de inserção econômica internacional da América Latina.

A transformação produtiva deveria, também, promover a equidade e a harmonia social, modificando o padrão de acumulação com incrementos na produtividade e menos depreciação dos salários reais. A industrialização por substituição de importações não absorveu diversas classes de trabalhadores urbanos e grupos camponeses. A transformação social requerida deveria ser capaz de consolidar uma base social de sustentação. Para Rodríguez (2009, p. 522), "pode-se dizer que, como componentes da base social da estratégia proposta, destacam-se os empresários nacionais, na base empresarial pública, ligada a entidades conformadas pelo Estado, as classes trabalhadoras urbanas (incluídas as de muito baixo nível de produtividade e remuneração), os grupos camponeses e os impulsionadores das atividades técnicas e científicas."

Para tanto, dever-se-ia fomentar a criação da chamada "nova aliança" sociopolítica, com foco na atividade de condução do processo industrial pelo empresariado nacional. A liderança deveria partir de empresários da atividade produtiva, e não da elite do setor financeiro transnacional. A proposta de Fajnzylber era de que "uma base de empresários nacionais que vão perfilando e definindo seus objetivos, arraigados em seu próprio país e território, constitui a via segura para ir gerando ou absorvendo progresso técnico e, inversamente, para atenuar o risco de que os esforços por obtê-lo sejam realizados de modo principal ou exclusivo fora de fronteiras" (RODRíGUEZ, 2009, p. 535).

Além disso, os atores sociais não abarcados pelo desenvolvimento gerado até então, deveriam ser inseridos na distribuição dos ganhos gerados pelo progresso técnico. A equidade do processo de desenvolvimento seria agora prioritária, e os aumentos de remuneração deviam ser seguidos por uma melhor distribuição da renda. Novas formas inclusivas de organização política também deveriam ser fomentadas. A vertente neoestruturalista cepalina passa, então, a analisar não somente as possibilidades de acumulação de capital e progresso técnico via comércio internacional, mas a buscar entender de que forma essa acumulação se dá na América Latina. Além disso, era necessário buscar soluções para a concentração de renda reforçada pelo processo de industrialização.

Uma das formas possíveis de distribuição equitativa dos ganhos gerados pelo progresso técnico seria a qualificação da mão de obra, o que possibilitaria aumentos de remuneração. $O$ aspecto educacional também aparece na análise como forma de propagação do desenvolvimento para toda a sociedade, bem como de superação do aspecto de mimetização industrial. Nesse sentido, novamente explicita-se a necessidade de melhoria na aprendizagem via atitude criativa anteriormente apresentada.

O Estado deveria atuar conjuntamente com a sociedade civil, buscando promover medidas redistributivas que possibilitassem uma diminuição na heterogeneidade social. Tais medidas são citadas no documento "Transformación productiva con equidade" 
(1996), como os programas de qualificação destinados a microempresários, trabalhadores autônomos e agricultores. Além disso, são consideradas reformas de mecanismos de regulação com vistas à formação de microempresas, a fim de se permitir a inclusão dos que permaneceram fora do processo de desenvolvimento ocorrido até então.

O novo contexto de competitividade internacional também deveria ser absorvido nas análises neoestruturalistas. A necessidade de obtenção de divisas e a superação da vulnerabilidade externa ainda vigente, deveriam ser tratadas a partir do novo contexto de economias globalizadas. O referido documento cepalino de 1996 trata do avanço da "renda perecível" dos recursos naturais para a "renda dinâmica" da incorporação do progresso técnico na atividade produtiva, mostrando, assim, a continuidade do problema da deterioração dos termos de troca (CEPAL, 1996, p. 14).

A competitividade internacional passou a ser entendida como sistêmica, ou seja, as empresas estão inseridas em um contexto institucional socioeconômico e ambiental específico e integrado. Assim, modificar a estrutura produtiva envolveria promover uma integralização setorial, respeitadas as particularidades e os limites ambientais. A indústria continuaria sendo o eixo para tal transformação, e as proteções e incentivos até então concedidos a alguns setores deveriam ser gradativamente superados à medida que a produtividade e a competitividade aumentassem.

O conceito de competitividade sistêmica foi cunhado por Fajnzylber (2000) a partir da observação histórica da inserção no mercado internacional das economias japonesa, alemã e sul-coreana. Esses países, por carecerem de recursos naturais abundantes, tiveram como única possibilidade de inserção internacional a industrialização. Os altos níveis de investimento em setores estratégicos, juntamente com modificações nas relações trabalhistas, visando a torná-las mais harmoniosa e cooperativa, contribuíram para que a competitividade nesses países ocorresse de modo sistêmico.

O foco da intervenção estatal após 1990 passaria a ser a promoção da competitividade industrial a partir de absorção de progresso técnico. O Estado deveria conceder incentivos prioritariamente às atividades inovadoras, gerando maior incorporação de progresso técnico e núcleos endógenos de inovação tecnológica - conceito criado por Fajnzylber em linha com a ideia neoschumpeteriana de sistema nacional de inovação ${ }^{6}$.

A nova política industrial, proposta pela Cepal, tem como base, portanto, uma vertente neoschumpeteriana, admitindo a intervenção estatal em indústrias específicas e fomentando o desenvolvimento empresarial privado, bem como tomando medidas em áreas como infraestrutura, educação, formação de recursos humanos, regulação e incentivos. Tal política deveria considerar o sistema econômico como um todo e promover uma competitividade sistêmica e um novo modelo de inserção internacional (SUZIGAN; FERNANDES, 2004).

A competitividade internacional é problematizada a partir da continuidade das assimetrias tecnológicas entre os países centrais e periféricos. A divergência e a concentração tecnológica nos primeiros continuavam sendo incrementadas apesar do avanço industrial nos últimos:

\footnotetext{
${ }^{6}$ Inovação entendida a partir da interação estruturada entre diversos agentes econômicos de forma sistêmica e não linear.
} 
La globalización ha dado origen no sólo a una creciente interdependencia, sino también a marcadas desigualdades internacionales. Para expresarlo en contraste con un concepto ampliamente utilizado en los debates recientes, la economía mundial es un "campo de juego" esencialmente desnivelado, cuyas características distintivas son la concentración del capital y la generación de tecnología en los países desarrollados, y su fuerte gravitación en el comercio de bienes y servicios. Estas asimetrías características del orden global constituyen la base de las profundas desigualdades internacionales en términos de distribución del ingreso (CEPAL, 2002, p. 77).

Entre os principais motivos das disparidades estão o crescimento de conglomerados transnacionais, cujos núcleos decisórios ficavam nos países centrais, e a crescente mobilidade de capitais ocasionada pela globalização. Assim, os ganhos de produção eram, em sua maior parte, transferidos aos países sede das empresas transnacionais. A estrutura produtiva das economias latino-americanas continuou defasada e a heterogeneidade não foi resolvida, ou até agravada, com base no modelo de desenvolvimento adotado até então.

Daí o ensejo para o desenvolvimento de um novo modelo de industrialização que levasse em consideração não apenas as particularidades históricas da região, mas também contemplasse a nova realidade internacional observada a partir da última década do século 20.

\section{A CEPAL NA CONTEMPORANEIDADE: Uma Guinada Rumo à Ortodoxia?}

Desde os anos 1990, as ideias neoliberais tornaram-se o pensamento dominante no cenário político-ideológico latino-americano. As propostas cepalinas dos anos 1950 e 1960 necessitaram sofrer adaptações à nova realidade vigente para que a comissão não apenas se adequasse às novas condições impostas por uma economia diferente da qual havia sido forjada, mas também para exercer alguma influência nos governos de vertentes neoliberais. José Gabriel Palma (2009) descreve esse cenário da seguinte forma: "(...) not even the Latin American left that has so far resisted the neo-liberal tsunami has been able to generate a new tradition of critical thought; hence the neo-liberal slogan "there is no alternative" has become one of the most effective self-fullfilling prophecies $\operatorname{ever}^{\prime \prime 7}$ (p. 243).

A própria defesa da industrialização nos países periféricos não mais levaria ao fortalecimento nacional, dado o interesse dos conglomerados transnacionais e do capital financeiro em dominar tal setor. As agendas progressistas dos governos latino-americanos foram permeadas por medidas pró-mercado a fim de se atrair capitais internacionais. Ainda de acordo com Palma (2009), posições genuinamente de esquerda mostraram-se basicamente extintas no horizonte dos países periféricos.

7 "nem mesmo a esquerda latino-americana que até agora resistiu ao tsunami neoliberal foi capaz de gerar uma nova tradição de pensamento crítico; portanto, o slogan neoliberal "não há alternativa" tornou-se uma das profecias autorrealizáveis mais eficazes de todos os tempos". 
A renovação do pensamento cepalino sobre o desenvolvimento da região mostra-se necessária diante do baixo crescimento apresentado até então, visto como erro na execução das ideias anteriores e como consequência da guinada neoliberal globalizada pós 1990. Assim, correntes heterodoxas, como as pós-keynesianas, marxistas, institucionalistas e evolucionistas, vêm sendo adaptadas pelo pensamento cepalino sem contraporem-se à economia de mercado, de forma a tornarem-se aceitas em um contexto de ascensão neoliberal (MISSIO; JAYME JUNIOR, 2012).

Nesse sentido, o projeto cepalino modificou suas pautas para uma agenda internacional de desenvolvimento em detrimento de ideais nacionalistas. O pensamento crítico passou a abarcar temas como desigualdade de gênero, democracia, desigualdade social, população indígena, energia renovável, entre outros campos em que a heterodoxia não conflitaria com questões macroeconômicas de eficiência de mercado, mas focaria, sobretudo, na questão da equidade.

O desenvolvimento passou a ser visto como um processo totalizante e, a partir de análises que extrapolam a seara econômica, envolvendo o âmbito social, político e cultural. O foco no agente empresarial como condutor nas transformações tecnoprodutivas, considerando um Estado redutor das incertezas inerentes ao mercado, condiz com as políticas públicas de um momento em que se procura a "ação conjunta de agentes públicos e privados e não necessariamente uma política estatal" (RODRÍGUEZ, 2009). Tal conjunção de esforços entre as esferas pública e privada mostrava a adaptação do intervencionismo Estatal proposto nos anos 1990/1960 para a nova realidade pós-abertura econômica. O peso do Estado nas análises cepalinas foi atenuado ao se reconhecer a importância de uma democracia consolidada que permita a atuação dos agentes privados em um ambiente apenas regulado pelo Estado.

A plena garantia dos direitos individuais para todos os integrantes da sociedade também se tornou pauta recente, considerando, principalmente, o aumento dos movimentos migratórios e conflitos sociais na região. Condizente com os ideais defendidos pela ONU, a defesa da pluralidade e o fortalecimento do espaço público e democrático tornaram-se a temática principal da comissão. A busca por coesão social justifica-se, pois, no entendimento de Rodríguez (2009, p. 643), "existe uma relação positiva e estimulante entre coesão social e igualdade, já que a primeira promove valores de solidariedade e responsabilidade que favorecem a destinação de recursos a objetivos de reversão da iniquidade". Assim, busca-se a inserção de grupos culturalmente discriminados, de modo que as identidades culturais latino-americanas passaram a ser protegidas após anos de imitação cultural dos países centrais. O processo globalizatório não poderia visar a uma homogeneidade cultural; agora, o processo de desenvolvimento passa a ser visto também como um ato cultural, no sentido dado por Furtado (1961).

Novas estratégias para uma agenda do desenvolvimento estavam sendo delineadas, portanto, ao se considerar um sistema cultural periférico inserido em um sistema global. Nesse sentido, o papel do Estado volta a ser primordial na garantia das relações sociopolíticas internas bem como nas relações geopolíticas internacionais. Além disso, a resolução dos problemas ocupacionais também deveria ser função do Estado, posto que a questão não se resolveu apenas com a livre-operação dos mercados, e a heterogeneidade ocupacional foi ainda agravada nas décadas de 80 e 90 do século 20. 
O processo tecnológico acarretou uma nova forma de divisão de trabalho, permanecendo a periferia, no entanto, excluída dos avanços gerados nos países centrais. A chamada estratégia mista de desenvolvimento consistiria em promover exportações e, concomitantemente, fortalecer o mercado interno. A exportação de manufaturas da periferia, no entanto, permanecia dificultada principalmente por questões relacionadas à assimetria de poder. Isso ocorre porque os benefícios da globalização também foram distribuídos de maneira assimétrica, em claro favor dos países centrais. Tais economias beneficiaram-se da abertura dos mercados para seus produtos e foram capazes de proteger os interesses de suas indústrias nacionais. Além disso, puderam restringir a transmissão de tecnologias às estruturas periféricas em razão do avanço de empresas transnacionais.

A disparidade entre os mercados financeiros do centro e da periferia também ocasionou modificações nas propostas de desenvolvimento para a região. A financeirização da economia gerou uma nova vulnerabilidade, aumentando a dependência externa dos países que recorrem à poupança externa para financiarem seus déficits em transações correntes. Além disso, o endividamento em moeda estrangeira ocasionou nova problemática às políticas monetárias dos governos latino-americanos. Rodríguez (2009, p. 668) exemplifica o problema da seguinte forma:

Os mercados financeiros dos países em desenvolvimento são sensivelmente mais incompletos que os mercados internacionais, de tal modo que nesses países uma parte da intermediação financeira deve ser levada a cabo, necessariamente, naqueles mercados. Os mercados incompletos, em aliança com o fato de que as moedas internacionais são as dos centros, guardam relação com o caráter pró-cíclico dos fluxos de capital nos países em desenvolvimento. Durante os períodos de bonança, os recursos em que esses fluxos se sustentam são de fácil disponibilidade e concorrem para eles sem maiores obstáculos. No entanto, quando sobrevêm indícios de depressão, os agentes que acedem ao crédito externo (governos e grandes empresas) vêem-se submetidos com mais freqüência à perda de base monetária; e os que não possuem essa capacidade (empresas médias e pequenas) padecem do mesmo problema em termos de prazos.

Apesar do agravamento dos problemas estruturais após 1980, a América Latina foi capaz de auferir crescimento expressivo a partir dos anos 2000 devido ao boom de preços das commodities. Nesse período, o processo de industrialização perdeu força e um retorno às atividades primárias apresentou-se como estratégia de curto prazo. A reprimarização ocorrida modificou a pauta de exportações dos países da região (BRESSER-PEREIRA, 2012). Além disso, as taxas de desigualdade e a pobreza foram relativamente comprimidas, e os processos democráticos consolidaram-se, gerando uma onda de otimismo na região. Tais acontecimentos eram vistos por economistas ortodoxos como decorrentes da adequada instituição do modelo financeiro de livre-mercado, ainda que, em geral, políticas sociais também foram largamente desenvolvidas.

Após a crise financeira de 2008, no entanto, o paradigma econômico dominante vem sendo questionado, surgindo novos espaços de debate para a análise histórica neoestruturalista, que permanece sendo adaptada de acordo com a realidade vigente. Caldentey $(2015$, p. 52$)$ define tal adaptabilidade da metodologia como condizente ao sistema aberto da teoria neoestruturalista: 
En consonancia con el enfoque estructuralista tradicional, el neoestructuralismo puede caracterizarse, en sus distintas acepciones, como un sistema o conjunto de ideas abierto. Los sistemas abiertos no se consideran autocontenidos y analizan el comportamiento de los agentes y las estructuras económicas y sociales, y su interrelación, en un contexto histórico y evolutivo (son dinámicos y cambian en el tiempo con el contexto y las circunstancias).

Nesse sentido, a interpretação cepalina do subdesenvolvimento foi adaptada ao longo do tempo e passou a identificar-se cada vez mais com o funcionamento de organismos multilaterais e com sua função de instituição das Nações Unidas (ALMEIDA FILHO; CORRÊA, 2012, p. 11). A mudança de perspectiva condiz com uma abertura maior do "diálogo à direita e à esquerda do espectro retórico e ideológico internacional" (BIELSCHOWSKY, 2000, p. 64). A função primordial de pesquisas e diagnósticos socioeconômicos da região permanece e é adaptada à conjuntura mundial, mantendo a base de análise heterodoxa do subdesenvolvimento.

Em seu mais recente informe de 2019 - "Perspectivas do Comércio Internacional da América Latina e do Caribe" - a Cepal trata de questões da guerra comercial entre países centrais como fator agravante da vulnerabilidade externa das economias periféricas. Prevê-se a desaceleração do comércio mundial decorrente das tensões comerciais e tecnológicas entre Estados Unidos e China. A queda da produção industrial também é apresentada como um problema generalizado nas economias mundiais, inclusive nos países centrais.

O informe argumenta que a fragilidade das inversões na periferia deve-se, também, à queda dos investimentos estrangeiros diretos (IED) desde 2015, sendo a desaceleração do PIB mundial o principal responsável por essa diminuição de investimentos. Além disso, o novo cenário apresenta uma modificação na natureza do comércio, sugerindo um aumento de fluxo de informação digital em detrimento de bens e serviços.

A depreciação dos termos de troca também passa a ser questão chave para a região. A queda nos preços das commodities voltou a exacerbar o problema das economias voltadas à exportação de produtos primários, considerado pela comissão desde sua criação como um padrão de exportação obsoleto. Além da estrutura exportadora agrária, os fatores internos, apontados no documento de 2019, que comprometem o desempenho exportador da região, são o baixo crescimento do PIB latino-americano e a infraestrutura e logística de escoamento de produção ainda deficientes. De todo modo, a ideia original de ciclos econômicos de Prebisch (1982) é retomada. Sob essa ótica, o período atual é visto como um aprofundamento de um ciclo recessivo de demanda, ocasionado, principalmente, pelas tensões comerciais entre China e Estados Unidos, levando à queda dos preços das matérias-primas e aumento da vulnerabilidade comercial da América Latina.

A busca de sustentabilidade nos acordos comerciais também é a temática para os próximos anos, com uma preocupação especial em desincentivar, por exemplo, setores industriais com alto impacto ambiental e subsídios a energias renováveis. O conceito de "política industrial verde" foi usado por Alicia Bárcena, atual secretária-executiva da Cepal, na última conferência realizada no México. As questões de mudança climática são tratadas com alta prioridade pela comissão, na contramão de políticas adotadas por alguns países centrais. 
Observa-se, também, uma nova abordagem visando à diminuição da concentração de renda. Em uma coluna de opinião, publicada em 6 de novembro de 2019 Bárcena considera o período de crise do estilo de desenvolvimento vigente. Os atrasos estruturais e produtivos estão sendo exacerbados no modelo atual de políticas de austeridade e redução de investimento público e gastos sociais. Segundo Bárcena (2019), as novas perspectivas de análise são direcionadas da seguinte forma:

É necessário renovar o pensamento e a métrica sobre as desigualdades. É necessário medir a riqueza e não somente a pobreza. Incorporar a desigualdade na propriedade e não somente na renda. (...) reconheçamos que o atual estilo dominante de desenvolvimento é inviável e, também, produz um desenvolvimento escasso e distorcido por três razões fundamentais: porque produz pouco crescimento, porque gera e aprofunda desigualdades e porque é ambientalmente destrutivo. Um estilo de desenvolvimento que incentivou as expectativas de mobilidade social e o progresso e, portanto, dado o seu fracasso, há uma grande exasperação, impaciência e desencanto em relação a toda a classe política, especialmente nos jovens. Devemos reconhecer que as desigualdades são mais profundas, duradouras, inelásticas e resilientes do que normalmente pensamos. Hoje, essa realidade explode no desconforto dos povos de nossa região e exige que escutemos suas vozes e que construamos propostas de desenvolvimento que incluam todas e todos. É aberta a oportunidade de uma mudança civilizatória para a região onde são reconsiderados os pactos sociais com ampla participação dos cidadãos e com uma visão de médio e longo prazo. Chegou a hora da igualdade e de um novo estilo de desenvolvimento. É hora de repensar os pactos sociais e superar um modelo econômico baseado na cultura de privilégios que prioriza o interesse particular sobre o público, o capital sobre o trabalho, a acumulação sobre a redistribuição, o crescimento sobre a natureza, os privilégios sobre os direitos, a diferenciação social sobre a equalização, as hierarquias sobre os relacionamentos horizontais. Hoje, as Nações Unidas e a CEPAL devem redobrar seus esforços para construir propostas baseadas em evidências que permitam superar o fardo da desigualdade e que deem aos nossos povos a dignidade que merecem (Grifo nosso).

É importante mencionar que tal documento foi publicado após o acirramento de manifestações populares em países da região contra políticas neoliberais adotadas pelos governos, especialmente no Chile. De acordo com a autora, "no Chile, por exemplo, com um PIB per capita de 25 mil dólares ao ano, a metade dos trabalhadores recebe um salário inferior a 550 dólares por mês e praticamente todos os serviços - educação, saúde, medicamentos, transporte, eletricidade, água, etc. - impactam os gastos dos assalariados. Em termos de patrimônio, o $1 \%$ mais rico detém $26,5 \%$ da riqueza, e os $10 \%$ mais ricos concentram $66,5 \%$, enquanto os $50 \%$ mais pobres têm acesso a somente 2,1\% da riqueza do país" (BÁRCENA, 2019).

Isto posto, entende-se que não há uma guinada ortodoxa do organismo. O pensamento neoestruturalista evoluiu de acordo com a conjuntura global, necessitando adaptar alguns ideários iniciais, como o grau de intervenção estatal à nova realidade

\footnotetext{
${ }^{8}$ Disponível em: https://www.cepal.org/pt-br/articulos/2019-chegou-hora-igualdade-america-latina-caribe-urgencia-sem-atraso
} 
por que passa a região e o mundo. Vê-se, assim, a atualidade na análise cepalina e a constante adaptabilidade do método histórico-neoestruturalista, tido por Bielschowsky (2000) como o principal ativo intelectual cepalino:

O laboratório de experiências inovadoras em que a América Latina se transformou a partir das reformas generalizadas nos anos 1990, junto com o novo cenário mundial, oferece um campo fértil para trabalhos de investigação com esse enfoque metodológico. Como nenhuma outra instituição, a CEPAL encontra-se preparada para identificar e analisar as complexidades das economias e sociedades latino-americanas nessa virada de milênio. Cabe, uma vez mais, aproveitar ao máximo a oportunidade histórica (p. 68).

As adaptações da análise cepalina às condicionalidades da região deverão guiar o desenvolvimento futuro da teoria cepalina. O foco atual na superação do subdesenvolvimento é a busca por igualdade, pela preservação ambiental e pela construção de um Estado de bem-estar social.

Diante dos elementos apresentados, argumenta-se que, a despeito das inegáveis adaptações sofridas pela teoria cepalina original desde a sua consolidação como principal think tank gerador e difusor de conhecimento econômico na periferia do capitalismo, o chamado neoestruturalismo não rompeu com os paradigmas fundantes do pensamento original. Indo além, defende-se que tais elementos foram, inclusive, reforçados, uma vez que o cerne - ou a estrutura - da política econômica cepalina manteve-se fiel ao arcabouço inicialmente desenvolvido por Prebisch (1982).

A noção de que países periféricos, ainda que industrializados, deveriam adotar estratégias diferentes das advogadas pela economia liberal mainstream, permeia toda a atualização do pensamento cepalino. Reconhece-se que as medidas por meio das quais tais economias deveriam inserir-se na nova divisão internacional do trabalho, foram qualificadas à luz da realidade material e ideológica do mundo pós-guerra fria. Ainda assim, advoga-se que somente pela remodelação estrutural dos respectivos tecidos produtivos é que tais economias poderão atingir o almejado patamar econômico, político, social e ambiental em que se encontram determinados países centrais; em outros termos, o desenvolvimento.

\section{CONSIDERAÇÕES FINAIS}

A constituição de um centro de pensamento econômico heterodoxo na periferia do capitalismo mundial representou, com efeito, uma ousadia perante o soft power norte-americano do pós-Segunda Guerra. Resultado do esforço de homens e instituições, a Cepal pode ser considerada um marco da união dos países latino-americanos no século 20. Mais do que a criação, porém, trata-se da perenidade da influência da comissão sobre intelectuais e policymakers, o resultado mais profícuo do empreendimento levado a cabo por personagens de destaque na história do subcontinente.

Os 70 anos de produção intelectual da Comissão Econômica para a América Latina e o Caribe são marcados pela fidelidade ao método histórico-estrutural da análise em sua trajetória. Com as mudanças de conjuntura econômica da região e mundial, as propostas foram sendo adequadas com vistas ao melhoramento da estrutura produtiva 
e social dos países do subcontinente. As cinco teses originárias também permanecem atuais na medida em que a heterogeneidade social e a especialização estrutural se agravaram a partir do processo globalizatório9.

A América Latina segue, contudo, como uma das regiões mais desiguais do mundo, apresentando alta concentração de renda e patrimônio nas camadas mais ricas. Os problemas estruturais permanecem e a vulnerabilidade externa não foi corrigida; ao contrário, o aumento da incerteza no cenário internacional potencializou tais vulnerabilidades nos períodos recentes. Tal conjuntura é percebida e analisada pelas publicações mais recentes da comissão, que apresentam, de forma mais clara, o caráter social que passou a balizar seus estudos.

Nota-se, assim, que o pensamento cepalino é constantemente atualizado, considerando a realidade da região e se propondo a entender e sugerir soluções a seus problemas estruturais, como a alta concentração de renda e a instável integração intrarregional. As mudanças na trajetória das instituições são absorvidas pela teoria cepalina, a qual incorpora esses elementos à análise do subdesenvolvimento histórico da região.

O subdesenvolvimento latino-americano permanece como objeto maior da teoria cepalina. Sendo uma comissão ligada a um organismo multilateral e representante de governos da região, a Cepal, apesar de ter absorvido influências teóricas plurais, foi capaz de manter sua autonomia intelectual, apresentando alternativas às políticas de cunho neoliberais. Conquanto entendimentos em contrário levantem questões pertinentes a sustentar uma suposta mudança de paradigma a partir dos anos 1990, conclui-se que a fidelidade à essência do pensamento estruturalista/neoestruturalista se manteve uma constante no decorrer das sete décadas de existência da instituição.

\section{REFERÊNCIAS}

ALMEIDA FILHO, N.; CORRÊA, P. V. A Cepal ainda é uma escola do pensamento? In: ETGES, V. E.; AREND, S. C. (org.). Cepal: leituras sobre o desenvolvimento latino-americano. Santa Cruz do Sul: Edunisc, 2012. BÁRCENA, A.; PRADO, A. Neoestructuralismo y corrientes heterodoxas en América Latina y el Caribe a inicios del siglo XXI. Libros de la Cepal, Santiago de Chile: Comisión Económica para América Latina y el Caribe (Cepal), n. 132 (LC/G.2633-P/Rev.1), 2015.

BÁRCENA, A. Coluna de opinião, 6 de novembro de 2019. Disponível em: https://www.cepal.org/pt-br/ articulos/2019-chegou-hora-igualdade-america-latina-caribe-urgencia-sem-atraso.

BIELSCHOWSKY, R. Cinqüenta anos de pensamento na Cepal. Uma resenha. In: BIELSCHOWSKY, R. (org.). Cinqüenta anos de pensamento na Cepal. Rio de Janeiro: Record, 2000.

BIELSCHOWSKY, R. Sesenta años de la Cepal: estructuralismo y neoestructuralismo. Revista de la Cepal, $\mathrm{n}$. 97, 2009.

BRESSER-PEREIRA, L. C. Desprotecionismo e desindustrialização. Valor Econômico, São Paulo, 2012.

CALDENTEY, E. P. Una coyuntura propicia para reflexionar sobre los espacios para el debate y el diálogo entre el (neo)estructuralismo y las corrientes heterodoxas. In: BÁRCENA, A.; PRADO, A. Neoestructuralismo y corrientes heterodoxas en América Latina y el Caribe a inicios del siglo XXI. Libros de la Cepal, Santiago de Chile: Comisión Económica para América Latina y el Caribe (Cepal), n. 132 (LC/G.2633-P/Rev.1), 2015.

\footnotetext{
${ }^{9}$ De acordo com Rodríguez (2009), pode-se resumir as cinco teses originárias da Cepal em: (1) visão dicotômica centro-periferia; (2) inelasticidade da oferta agrícola; (3) deterioração dos termos de troca; (4) industrialização como meio de superação do subdesenvolvimento; e (5) planejamento estatal como instrumento para se coordenar a alocação ótima dos recursos com vistas à industrialização.
} 
CEPAL. Comisión Económica para América Latina y el Caribe. La Matriz de la desigualdad social en América Latina. Libros de La Cepal, Santiago de Chile: Comisión Económica para América Latina y el Caribe (Cepal), (LC/G.2690), 2016. Disponível em: https://repositorio.cepal.org/bitstream/handle/11362/40668/ S1600946_es.pdf?sequence=4\&isAllowed=y. Acesso em: 1으ov. 2019.

CEPAL. Comisión Económica para América Latina y el Caribe. Globalización y desarrollo. Libros de La Cepal, Santiago de Chile: Comisión Económica para América Latina y el Caribe (Cepal), (LC/G.2157), 2002. Disponível em: https://repositorio.cepal.org/bitstream/handle/11362/2724/2/S2002024_es.pdf. Acesso em: 5 nov. 2019.

CEPAL. Comisión Económica para América Latina y el Caribe. Perspectivas do Comércio Internacional da América Latina e do Caribe, 2019 (LC/PUB.2019/21-P). Santiago, 2019. Disponível em: https://repositorio. cepal.org/bitstream/handle/11362/44940/1/S1900749_pt.pdf. Acesso em: 14 nov. 2019.

CEPAL. Comisión Económica para América Latina y el Caribe. Políticas de ajuste e renegociação da dívida externa da América Latina. In: BIELSCHOWSKY, R. (org.). Cinqüenta anos de pensamento na Cepal. Rio de Janeiro: Record, 2000a.

CEPAL. Comisión Económica para América Latina y el Caribe. Transformação e crise na América Latina e Caribe 1950-1984. In: BIELSCHOWSKY, R. (org.). Cinqüenta anos de pensamento na Cepal. Rio de Janeiro: Record, 2000b.

CEPAL. Comisión Económica para América Latina y el Caribe. Transformación productiva con equidad. Libros de la Cepal, Santiago de Chile: Comisión Económica para América Latina y el Caribe (Cepal), n. 25 (LC/G.1601-P), 1996. Disponível em: https://www.cepal.org/es/publicaciones/2102-transformacion-productiva-equidad-la-tarea-prioritaria-desarrollo-america-latina. Acesso em: 23 out. 2019.

FAJNZYLBER, F. Industrialização na América Latina: da "caixa-preta" ao "conjunto vazio". In: BIELSCHOWSKY, R. (org.). Cinqüenta anos de pensamento na Cepal. Rio de Janeiro: Record, 2000.

FURTADO, C. Desenvolvimento e subdesenvolvimento. Rio de Janeiro: Editora Fundo de Cultura, 1961.

FURTADO, C. Criatividade e dependência na civilização industrial. Rio de Janeiro: Paz e Terra, 1978.

FURTADO, C. Cultura e desenvolvimento em época de crise. Rio de Janeiro: Paz e Terra, 1984.

FURTADO, C. A fantasia organizada. Rio de Janeiro: Paz e Terra, 1985.

MISSIO, F. J.; JAYME JUNIOR, F. G. Estruturalismo e neoestruturalismo: velhas questões, novos desafios. Análise Econômica, v. 30, n. 57, p. 205-230, 2012.

PALMA, J. G. Why did the Latin American critical tradition in the social sciences become practically extinct? In: BLYTH, M. (org.). Routledge handbook of international political economy (IPE): IPE as a global conversation. New York: Routledge, 2009.

PREBISCH, R. Crecimiento, desequilibrio y disparidades: Interpretación del proceso de desarrollo económico. In: GURRIERI, A. La obra de Prebisch en la Cepal. México: Fondo de Cultura Económica, 1982.

RODRÍGUEZ, O. O estruturalismo latino-americano. Rio de Janeiro: Civilização Brasileira, 2009.

SUNKEL, O.; ZULETA, G. Neoestructuralismo versus neoliberalismo em los años noventa. Revista de La Cepal, n. 42, 1990.

SUZIGAN, W.; FERNANDES, S. C. Competitividade sistêmica: a contribuição de Fernando Fajnzylber. História Econômica \& História de Empresas, v. 7, n. 2, 2004. 